\title{
Conmemoración y demandas de justicia en torno a la muerte de un líder senegalés en Argentina
}

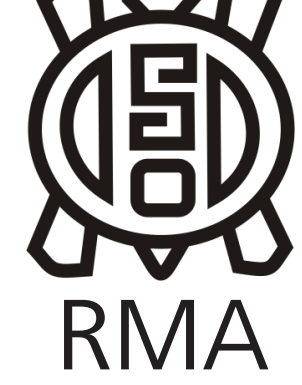

Antropología Social
Conmemoration and justice demands about the death of a senegalese
leader in Argentina

Paola C. Monkevicius

CONICET, Facultad de Ciencias Naturales y Museo, Universidad Nacional de La Plata, Argentina. E-mail: pmonkev@gmail.com

\begin{abstract}
Resumen
En el presente artículo analizamos los sentidos públicos que se producen, transmiten y disputan acerca de la muerte (entendida como crimen racista) del activista senegalés Massar Ba por parte del colectivo conformado por inmigrantes africanos y afrodescendientes en Argentina, en particular el significado que adquiere este acontecimiento en el contexto de una movilización conmemorativa. A partir del trabajo etnográfico realizado en este marco indagamos sobre los procesos de construcción de memorias subalternas y su relación con las "nuevas" formas de visibilización de negritudes en Argentina. Especificamente, a través del caso de Massar Ba, observamos cómo la recordación de la violencia racista e institucional opera en el presente de los afroargentinos para disputar narrativas hegemónicas de blanquedad e igualdad y, en consecuencia, demandar por derechos históricamente negados. En este proceso consideramos que los sectores de liderazgo afrodescendiente ocupan una posición privilegiada para fijar los parámetros tendientes a la recordación de la alteridad racializada.
\end{abstract}

Palabras clave: Memorias; Conmemoración; Violencia institucional; Afrodescendientes; Migrantes africanos.

\begin{abstract}
In this article we propose to explore the public senses about the death of the senegalese activist Massar Ba (understood to mean a racist crime) from the colective integrated by Africans and Afrodescendants in Argentina, in particular the meaning that the event acquires in the conmemorative movilization context. Based on the etnographic fieldwork, we analize the construction process of subaltern memories and its relation with the "new" ways of blackness visibilization in Argentina. Specifically, through Massar Ba case, we observe how the remembering of racist and institutional violence acts in the afroargentine present to dispute whiteness hegemonic and equality narratives and therefore to demand historically denied rights. In this process we consider that Afrodescendant leaders have a privileged position to determine the parameters aimed at recalling the racialized otherness.
\end{abstract}

Keywords: Memories; Conmemoration; Institutional violence; Afrodescendants; African migrants.

En la madrugada del 7 de marzo de 2016 el senegalés Massar Ba fue encontrado en grave estado en la vía pública. Al día siguiente falleció en un hospital porteño al cual había sido trasladado luego de un llamado al 911. Estas circunstancias obligaron a la intervención de la policía y del poder judicial, y provocaron una gran conmoción dentro del colectivo afroargentino, donde se vieron involucrados y movilizados tanto los inmigrantes senegaleses nucleados en asociaciones como algunos sectores conformados por afrodescendientes. Aunque todavía no se encuentra determinado si se trató de un homicidio $y$, en este caso, quiénes serían los posibles autores, los líderes y voceros de la comunidad interpretan el hecho en clave de la persecución institucional y violencia racista ejercida históricamente contra la población de origen africano. Esto demandó la necesidad no solo de difundir el hecho a través de las redes sociales, blogs y medios de comunicación, sino de participar activamente organizando diversos reclamos y movilizaciones tendientes a lograr el pronto esclarecimiento del caso. Dentro de este accionar nos interesa situarnos particularmente sobre la convocatoria realizada el 21 de marzo de 2016 frente a la fiscalía interviniente y la posterior marcha hacia el palacio de Tribunales donde se encuentra el juzgado encargado del caso. Esta movilización se realizó solo unos días después de la muerte de Massar Ba y en coincidencia con el aniversario en el cual se conmemora el Día Internacional de la Eliminación de la Discriminación Racial, fecha que hace referencia a la masacre ocurrida en Sharpeville, Sudáfrica ${ }^{1}$. En consecuencia, en el presente trabajo nos

\footnotetext{
1 Debemos mencionar que esta movilización se reiteró en la misma fecha de 2017 pero con una participación y alcance menores. Además se produjeron reiterados pedidos de justicia en diversos encuentros organizados por el colectivo afro durante 2016 y 2017.
} 
preguntamos acerca de los sentidos públicos que se producen, transmiten y disputan acerca de la muerte (entendida como crimen racista) del activista senegalés Massar Ba por parte del colectivo conformado por inmigrantes africanos y afrodescendientes, en particular el significado que adquiere este acontecimiento respecto a las formas de (des)articulación entre diversos sectores de liderazgo y el estado, en tanto interlocutor central y objeto de interpelación. Específicamente, nos interesa indagar estos procesos en el marco de la reconstitución de memorias subalternas focalizando sobre el carácter conmemorativo que adquiere la movilización realizada en la vía pública, la cual recrea una relación de continuidad entre los actos racistas perpetrados en Sudáfrica por el Apartheid y el asesinato de Massar Ba considerado como producto de la violencia institucional. De esta manera veremos cómo la apelación a un pasado de persecuciones y matanzas opera en el presente de los afroargentinos para reclamar políticamente derechos ciudadanos negados.

Para tal fin contamos con los datos obtenidos del trabajo etnográfico realizado en el marco de la marcha mencionada y de aquellos surgidos de la consulta realizada en diferentes sitios digitales (blogs, páginas de facebook, páginas web pertenecientes a las asociaciones y organizaciones afro, a los organismos estatales, a los medios de comunicación, entre otros) donde se han publicado entrevistas e imágenes obtenidas durante la movilización conmemorativa.

\section{La racialización de la muerte}

En principio diremos que Massar Ba se encontraba entre los primeros migrantes senegaleses arribados a la Argentina a mediados de la década de $1990^{2}$. Oriundo de Médina, en la ciudad de Dakar, realizó estudios en instituciones religiosas islámicas que luego continuó en la Universidad de Buenos Aires, específicamente en la carrera de Filosofía. Además de desempeñarse en empleos ligados a empresas de software y turismo, Massar Ba desarrolló una activa militancia tendiente a la defensa de los derechos de otros migrantes senegaleses y a la difusión de su cultura en asociaciones como la Daira, la Casa de África, la Asociación de Residentes Senegaleses en Argentina (ARSA), la agrupación Xangó, Todos con Mandela, entre otras. En el último año se había comprometido intensamente contra la represión y el hostigamiento policial ejercidos hacia los vendedores ambulantes africanos (principal actividad económica

\footnotetext{
2 Provenientes de las etnias diola, en un principio, y wolof posteriormente, los senegaleses han arribado a la Argentina en busca de mejoras económicas pero también como estrategia familiar y de emancipación. Si bien muchos han decidido iniciar los trámites de refugio ante las autoridades argentinas (como estrategia para legalizar su situación), las causas políticas no se consideran determinantes de la emigración proveniente de ese país. A falta de datos oficiales, la Asociación de Residentes Senegaleses en Argentina (ARSA) estima que actualmente residen en el país alrededor de 2.500 senegaleses, en su mayoría llegados en la década del 2000. Véase Zubrzycki (2011).
}

desarrollada por estos inmigrantes) ${ }^{3}$, presentando denuncias y activando marchas y movilizaciones junto a organismos de defensa de los derechos humanos ${ }^{4}$. Algunos activistas afroargentinos y africanos establecen una relación de causalidad entre estas acciones -a lo que se suma el desalojo que sufrió junto con otros senegaleses del departamento que ocupaban solo un mes antes del hecho- y su súbita muerte ocurrida en los primeros meses de 2016. Más precisamente, fue hallado herido e inconsciente en el barrio de Montserrat de la ciudad de Buenos Aires. Luego de una breve agonía, producto de los golpes sufridos, falleció en el hospital público Ramos Mejía. Las dudas sobre las causas de la muerte se vieron acrecentadas por el accionar policial en cuanto a la tardía realización de las pericias correspondientes y por la decisión judicial de caratular el hecho como "muerte dudosa" sin ordenar pericias posteriormente. Ante esta situación, un grupo de asociaciones que nuclean a afrodescendientes e inmigrantes africanos, junto con diversas organizaciones de defensa de los derechos humanos, emitieron un comunicado reclamando:

- Que se esclarezcan los hechos, se investigue profundamente y se encuentre y encarcele a Ixs culpables del crimen de Massar.

- Que se investigue el motivo de su muerte con una perspectiva integral, antidiscriminatoria y antirracista, no descartando la violencia institucional.

- Que se acepte como querellante a la Asociación de Residentes Senegaleses en la Argentina para que se garantice que no quede en la impunidad y el olvido la muerte de Massar. ${ }^{5}$

Para legitimar y sustentar estas demandas, la ARSA solicitó la intervención del Defensor General Adjunto del Ministerio Público de la Defensa de la Ciudad de Buenos Aires, Luis Duacastella, tanto para que observe y monitoree la investigación como para que patrocine el pedido de la conformar la querella. Según el presidente de la asociación, siendo que "Massar Ba no cuenta con familia en la Argentina" y Senegal carece de representación diplomática en el país "la Asociación quiere presentarse como querellante para estar muy cerca de la investigación, aportar todos los datos pero también insistir en que se haga justicia lo más rápido posible"6. Esta petición

\footnotetext{
${ }^{3}$ Como señala Espiro (2017), "si bien algunos senegaleses obtuvieron la residencia argentina mediante el programa de regularización, otra parte no cuenta con los títulos habilitantes necesarios para residir o para trabajar [poseen una habilitación de residencia temporal o "precaria"], y aunque esto no constituye una limitante para obtener un permiso o ejercer la venta ambulante -ya que logran abrirse paso y aprovechar la oportunidad de hacer negocios en esta región-, sí los coloca en una situación de mayor vulnerabilidad frente a los controles."

${ }^{4}$ Según afirma el comunicado de la ARSA emitido tras su fallecimiento. ${ }^{5}$ Comunicado de asociaciones, consultado en la página facebook de la Comisión Argentina para los Refugiados y Migrantes (CAREF) el 2 de diciembre de 2016. https://www.facebook.com/asociacion.caref/ ${ }^{6}$ Sintesis Comuna 3, publicación online destinada a brindar información sobre los barrios de Balvanera y San Cristóbal (Comuna 3) de la ciudad de Buenos Aires.
} 
obtuvo finalmente el dictamen negativo del juez, lo que provocó preocupación e inquietud entre varios sectores afro y de defensa de los derechos humanos (los cuales apelaron la medida) ya que limita su accionar frente a la posibilidad de un crimen institucional. Según Duacastella, la muerte podría deberse a "una situación de violencia institucional encubierta o un aspecto discriminatorio por la etnia a la que pertenecía"7. En esta línea, Florencia Mazzadi de la Asociación Cine Migrante, que integra la mesa de Cumplimiento efectivo de los Derechos Humanos de los migrantes, hace hincapié en la vulnerabilidad de Massar frente a la institución policial por su rol como "militante en Derechos Humanos, por [su] pertenencia racial y creencias religiosas [Ba era musulmán] y por su condición de inmigrante" ${ }^{\prime 8}$. Esto la movilizó a denunciar el hecho ante la Agencia Territorial de Acceso a la Justicia (ATAJO) del Ministerio Público Fiscal dependiente de la Procuración General de la Nación. La Agencia luego derivó la denuncia a la Procuraduría contra la Violencia Institucional (PROCUVIN), que solo se encuentra monitoreando el caso hasta que surjan evidencias de la intervención de agentes estatales. Según Christian Gruenberg, coordinador del Programa contra la Violencia Institucional del Ministerio Público de la Defensa, se debe realizar una investigación profunda debido al carácter de activista y referente del que gozaba Massar Ba entre los senegaleses e inmigrantes en general. Señala además que "su muerte se da en el marco del recrudecimiento de la violencia contra migrantes y vendedores ambulantes por parte de la policía" y se opone a que se descarte la violencia institucional como hipótesis principal ${ }^{9}$. Todos estos relatos coinciden en señalar que la clasificación por la raza se potencia cuando se solapa con la acción política, la (no) pertenencia nacional y la religión, marcando fuertemente al sujeto frente a los agentes estatales en tanto "peligroso" y, en consecuencia, pasible de punición.

A partir de lo expuesto hasta aquí, nos interesa destacar el lugar que adquiere el estado ${ }^{10}$ (sea de alcance nacional, provincial o local) en tanto objeto, por un lado, de las denuncias (o sospechas) sobre el ejercicio ilegal de la violencia (en este caso, sobre la población senegalesa) y, por el otro, de los reclamos por la igualdad de derechos. Ya en trabajos anteriores sostuvimos que ciertos sectores de liderazgo afrodescendiente interpelan al estado, que se posiciona (y es posicionado) de manera diferencial y

http://www.sintesiscomuna3.com.ar/amplia-nota.php?id_n=1487 Consultado el 12 de enero de 2017.

${ }^{7}$ Cosecha Roja, red de periodistas judiciales. http://cosecharoja.org/ marcha-para-pedir-justicia-por-la-muerte-de-massar-ba/ consultado el 10 de diciembre de 2016.

${ }^{8}$ Cosecha Roja, red de periodistas judiciales. http://cosecharoja.org/ marcha-para-pedir-justicia-por-la-muerte-de-massar-ba/ consultado el 10 de diciembre de 2016.

${ }^{9}$ Cosecha Roja, red de periodistas judiciales. http://cosecharoja.org/ marcha-para-pedir-justicia-por-la-muerte-de-massar-ba/ consultado el 10 de diciembre de 2016.

10 Debemos precisar que entendemos al estado no como un actor uniforme con formas de acción estandarizadas hacia los subalternos sino con heterogeneidades que complejizan estas intervenciones (Grimson 2013: 18). ambivalente: por un lado, como reproductor del racismo y la marginalización de sectores de la población de origen africano y, por el otro, como promotor del reconocimiento de derechos, específicamente hacia los afroargentinos históricamente relegados (Monkevicius 2017) ${ }^{11}$. Gaztañaga, Piñeiro Carreras y Ferrero (2016) lo plantean en términos de "efectos y afectos" que no se resuelven de manera contradictoria sino que se reconvierten en una relacion "constitutiva, de manera positiva, de las experiencias con el Estado, sus lógicas, sus agencias y sus campos de visión e invisibilización." En este caso es exhortado, a la vez, como posible responsable de la muerte de Massar $\mathrm{Ba}$, a través de un acto racista cometido por una acción represiva por parte de la institución policial, y como garante de la administración de justicia, a través del poder judicial y de los organismos de defensa de los derechos humanos.

Respecto a esto, resulta relevante profundizar el marco de interpretación dentro del cual se entiende a la muerte del líder senegalés como un acto derivado de la violencia racista.

\section{Nuevas categorías, nuevos racismos}

En principio diremos que luego del éxito del proyecto nacional de homogenización cultural promovido por las elites intelectuales y políticas de fines del siglo XIX y principios del siglo $X X$, las categorizaciones raciales $y$ étnicas se desdibujaron, siendo excluidas tanto de las lógicas de clasificación de los censos como de aquellas presentes en la vida cotidiana (Frigerio 2008). De la afirmación sobre que "en Argentina no había negros" se sigue entonces la aserción que aseguraba que "en Argentina no había racismo". A pesar de la desarticulación de las categorías étnicas y raciales en cuanto a su capacidad de clasificar a los sujetos, continuaron operando con gran firmeza procesos de racialización que reproducían y legitimaban desigualdades sociales. Se producía así un "silenciamiento de las dimensiones racial y étnica que, al tiempo que las sustraía del campo de lo politizable, las volvía operativas en su capacidad de negar a los otros" (Caggiano 2015: 172), Por lo tanto, la negación y la invisibilización de "lo negro" y "lo mestizo" constituyó lo que Frigerio (2006) denomina una "ceguera cromática". Dentro de esta construcción de lo nacional en torno al binomio blanquitud-negritud, se produjo una erosión de la alteridad racializada (Geler 2016) que operaba distinguiendo como "negras" a un número cada vez menor de personas que, debido a esta misma lógica, eran consideradas extranjeras. El resto de los afrodescendientes no reconocibles racialmente fueron demarcados a traves de categorías de clase (Frigerio 2006), las que explicaban y re-producían su posicionamiento subalternizado dentro del entramado social.

\footnotetext{
${ }^{11}$ Algunos funcionarios hablan de una "catarata de derechos" para los afroargentinos que se produjo durante los gobiernos de Néstor (20032007) y Cristina Kirchner (2007-2015).
} 
En los últimos años se observa un cambio gradual en el cual se van introduciendo matices a la clásica distinción entre blanquitud y negritud. Con la llegada de corrientes multiculturalistas se produce la "reaparición" de los negros en Argentina que revierte el silenciamiento a la vez que habilita a "nuevos" sujetos racializados, (auto) adscriptos como "afrodescendientes", "afroargentinos" o "afros", al introducir retóricas de opresión racista que habían permanecido silenciadas.

Para los objetivos de este trabajo resulta interesante observar cómo los reclamos por parte de los activistas afro (afrodescendientes e inmigrantes africanos), pugnando por el esclarecimiento de la muerte de Massar $\mathrm{Ba}$, ponen de manifiesto la forma en que "las negritudes portan sentidos de desprecio y exclusión que se remontan a los orígenes del sistema esclavista, y que aun en una Argentina supuestamente 'desracializada' se evidencian con toda su efectividad" (Geler 2016). A través de la realización de la marcha específicamente, los sectores de liderazgo afro introducen discursivamente el hecho policial dentro de una particular dinámica racista que, por un lado, invisibiliza y niega la presencia afrodescendiente dentro del colectivo nacional y, por el otro, re-produce formas de estereotipación, exotización, hipervisibilización que conllevan la vulnerabilidad de los sujetos racialmente demarcados.

\section{Las memorias en lucha}

En el presente apartado nos interesa detenernos sobre el marco en el cual se desarrolla esta demanda por derechos negados. En particular, sobre la marcha entendida como un acto conmemorativo siendo que se realiza en el día en que se celebra a nivel internacional la lucha contra el racismo. Específicamente se trata, como ya mencionamos, del Día Internacional de la Eliminación de la Discriminación Racial declarado en 1966 por las Naciones Unidas para recordar la masacre ocurrida seis años antes en Sharpeville, Sudáfrica, cuando la policía abrió fuego contra una manifestación pacífica que se oponía a las leyes de pases del Apartheid. A través de esta resolución, la Asamblea General de las Naciones Unidas se propuso "instar a la comunidad internacional a redoblar sus esfuerzos para eliminar todas las formas de discriminación racial"12.

Los sujetos con poder de decisión dentro del colectivo afro retoman la efeméride y la utilizan para situar el acto de pedido de justicia por Massar Ba. De esta forma, la fecha es elevada respecto del calendario quebrando el continuum histórico con el objeto de establecer el deber de recordar abriendo un marco de interpretación para la significación del pasado que une a los dos episodios en el plano simbólico. En otras palabras, la conmemoración se constituye en un vehículo de la memoria donde "las

\footnotetext{
12 http://www.un.org/es/events/racialdiscriminationday/background. shtml consultado el junio de 2017.
}

claves de lo que está ocurriendo en la subjetividad y en el plano simbólico se tornan más visibles, cuando las memorias de diferentes actores sociales se actualizan y se vuelven "presente"." (Jelin 2005), materializando sentidos subjetivos que a la vez que emergen en la esfera pública se convierten en objeto de debate.

Pocos días después del fallecimiento de Massar Ba y ante la falta de respuestas desde el poder judicial, diversos sectores de la dirigencia afroargentina decidieron manifestarse a través de una marcha que incluía un corte parcial de calles. La convocatoria provino desde varias asociaciones que nuclean a afrodescendientes y a africanos $^{13}$, y de organismos de defensa de los derechos humanos ${ }^{14}$ con el objeto de "que su recuerdo siga siendo vital y para que su lucha constante sea valorada y dignificada"15. La mañana del 21 de marzo, luego de fijar como punto de reunión un bar cercano, alrededor de 40 personas se dirigieron hasta la fiscalía séptima. El grupo se encontraba compuesto por inmigrantes africanos, afrodescendientes, activistas, académicos y miembros de los organismos de derechos humanos. Se encuentra aquí excluida la figura del familiar (Massar Ba no contaba con parientes en Argentina), clave como actor social en las demandas de justicia contra la violencia policial, situación que conlleva un vacío de afectividad en las discursos presentes en la protesta (Pita, 2010). ${ }^{16}$

Caminaron enarbolando pancartas que contenían la imagen del líder senegalés con la consigna "Justicia por Massar Ba" además de un extenso lienzo con la leyenda "Luchamos contra el racismo - Justicia por Massar Ba" sostenido por varias personas que lideraban la marcha. Se dirigieron lentamente hasta la entrada de la fiscalía mientras uno de los dirigentes gritaba las consignas de la bandera a la vez que era respondido con los gritos de "Basta" y "Justicia" por parte de los manifestantes. Si bien se trata de expresiones habituales en estos contextos, Pita (2010) señala que no solo deben entenderse como slogans o clichés sino como alusiones a una resistencia

\footnotetext{
13 Agrupación Xangó, Todos por Mandela, Sociedad Caboverdeana, África Vive, Asociación de Residentes Senegaleses en Argentina, (A.R.S.A), Asociación Misibamba, Instituto de Investigación y Difusión de las Culturas Negras, Asociación DAIRA, A Turma da Bahiana, Movimiento Afrocultural, Asociación ONIRA, A.P.O.A.A, lle Axe Alupo Bara y activistas afrodescendientes y africanos independientes.

${ }^{14}$ Organismos de Derechos Humanos: Madres de Plaza de Mayo Línea Fundadora, H.I.J.O.S Capital, Familiares de detenidos y desaparecidos por razones políticas, Liga Argentina por los Derechos del Hombre, Buena Memoria, Fundación Servicio Paz y Justicia, Asamblea Permanente por los Derechos Humanos, Comisión Argentina para los Refugiados y Migrantes (CAREF), Asociación de Mujeres Unidas Migrantes y Refugiadas en Argentina, Fundación Memoria Histórica y Social Argentina.

${ }^{15}$ Según comunicado emitido por las agrupaciones convocantes.

16 Sin embargo, entre los senegaleses específicamente existen fuertes lazos de solidaridad y reciprocidad que superan las relaciones de consanguinidad derivados en gran parte de su pertenencia a cofradías de origen musulmán que cobran gran relevancia durante el proceso migratorio (véase Zubrzycki, 2011). Tratándose de un grupo heterogéneo donde los afrodescendientes toman un rol central, la influencia de estos lazos deberá ser evaluada en futuras indagaciones.
} 
frente al poder de matar del estado. Se detuvieron frente a la puerta de los tribunales orales y pidieron ser recibidos por el fiscal de la causa. Luego de los trámites necesarios, lograron ingresar varios referentes de la comunidad, entre ellos, Carlos Álvarez, dirigente afrouruguayo de la asociación Afro Xangó y uno de los principales promotores de la protesta, Moustafá Sené, representando a los senegaleses, Miriam Gómez, líder del asociativismo caboverdeano, Manuel Altamiranda, director de la revista y la radio Dignidad Afrodescendiente, y Florencia Mazzadi, representante de la Asociación Cine Migrante. Al salir se dirigieron a los otros manifestantes que se encontraban rodeando la fiscalía y a los medios de comunicación que allí se habían convocado. Algunos tomaron la palabra para explicar la situación y luego decidieron movilizarse hasta el Palacio de Justicia ubicado en la calle Talcahuano, a pocas cuadras del lugar. Allí se encontraba el juez de la causa, quien se había negado a aceptar a la asociación senegalesa como querellante. La intención de los líderes afro era entrevistarse también con el juez. Mientras avanzaban, cortando parcialmente el tránsito de las calles, el dirigente afrouruguayo seguía clamando a viva voz las consignas de la manifestación. Al llegar solo lograron programar una entrevista con el juez los días posteriores. Allí nuevamente desplegaron la extensa bandera y repitieron el pedido de justicia. Finalmente se desconcentraron aunque los líderes y dirigentes prometieron seguir con la lucha para lograr el esclarecimiento del hecho.

En principio debemos mencionar que nos encontramos ante un colectivo heterogéneo atravesado por lazos de alianzas, consensos, pero tambien por disputas y conflictos irresueltos. A la par de esta heterogeneidad y volatilidad en el entramado social se despliegan estratificaciones, jerarquías, que se solidifican a traves de figuras de liderazgo, esto es, dirigentes, activistas, promotores culturales, que participan en asociaciones y agrupaciones con disímil grado de formalización. Detentan, por lo tanto, un mayor poder de decisión en cuanto a la producción de subjetividades y prácticas dentro del colectivo $y$, especialmente, en relación a la construcción de identificaciones y memorias en la esfera pública de interacción. En trabajos anteriores, y retomando a Jelin (2002a: 48), los definimos como "emprendedores de la memoria", es decir, como agentes generadores de "proyectos, de nuevas ideas y expresiones, de creatividad". Más específicamente, son los encargados de situar en el escenario público las disputas por las memorias, tratando de lograr el reconocimiento social y la legitimidad política de su versión del pasado (Jelin, 2002:49). Como señalamos arriba, son ellos quienes decidieron enmarcar el acto de reclamo de justicia dentro de un evento conmemorativo apropiándose de una fecha que recuerda la lucha contra el racismo a nivel mundial $y$, desde este contexto mnemónico, interpelar al estado, particularmente en cuanto al manejo y el accionar de las fuerzas de seguridad y a la administración de justicia. A su vez, establecen alianzas con aquellas reparticiones estatales encargadas de proteger los derechos humanos, en una relación ambivalente y compleja que también se encuentra atravesada por los (des)acuerdos con determinados agentes políticos y partidarios ${ }^{17}$.

A pesar de la pluralidad de asociaciones y activistas que adhirieron a la marcha solo unos pocos referentes se expresaron de forma pública asumiendo la representatividad del colectivo frente al estado. A traves de sus discursos en la puerta de la fiscalía encuadraron explícitamente la muerte de Massar dentro de un hecho de violencia institucional. El dirigente de la asociación senegalesa, de forma moderada, sostuvo que es necesario "saber quién o cuáles son las causas de la muerte de Massar Ba [...] estamos luchando contra cualquier acto de discriminación, de racismo y de xenofobia y creo que es una lucha muy justa que todos tenemos que estar involucrados en esta misma [...] nosotros necesitamos que se haga justicia". Por su parte, Carlos Álvarez, por la Agrupación Xangó, y Sandra Chagas, por el Movimiento Afrocultural, establecieron una relación concluyente entre la muerte del líder senegalés y la del joven afrouruguayo José Delfín Acosta Martínez ocurrida en el año 1996 luego de ser arrestado por la policía en la ciudad de Buenos Aires. Específicamente Chagas pidió justicia aseverando que Acosta "murió asesinado a golpes y patadas tambien por la policía". Por su parte, Álvarez recordó que "hace 20 años tambien mataron a Jose Acosta" y que el crimen aun se encuentra impune ${ }^{18}$.

De esta forma la protesta por la muerte de Massar Ba explicita la necesidad de recordar otros crímenes que se produjeron, según estos voceros de la comunidad, dentro de las mismas circunstancias de persecución y violencia. Existe, por lo tanto, junto al pedido de justicia, un deber de memoria que se apoya en hitos como la masacre de Sharpeville, donde el racismo estatal se manifestó de manera extrema y, a nivel local, el asesinato de José Acosta, en tanto acontecimiento que recuerda la continuidad de prácticas represivas que, "lejos de erradicarse, adquirieron modalidades diferentes a las de la dictadura, y se hicieron extensivas como modo de control y gobierno de los sectores de la población aún excluidas por el modelo de desarrollo." (Raggio 2017). Se establece así una secuencia narrativa de acontecimientos históricos que encuentran su origen en el sistema esclavista y cuyas consecuencias se extienden en un presente de desigualdad (Lao Montes 2009). Como afirma Miriam Gomes, representante de la asociación caboverdeana: "Justamente nosotros elegimos este día, para poner de

\footnotetext{
${ }^{17}$ Gran parte de esta dirigencia mantenía lazos políticos e ideológicos con representantes del gobierno anterior, presidido por Cristina Kirchner, lo que habilitaba su participación en diversas reparticiones del estado. Luego de las elecciones de 2015, y tras el cambio político del gobierno, esas relaciones debieron reconfigurarse.

${ }^{18}$ Debido a que las diversas instancias judiciales no lograron establecer la culpabilidad de los agentes policiales involucrados, el caso fue presentado ante la Comisión Interamericana de Derechos Humanos, la cual declaró admisible el caso.
} 
manifiesto lo que sigue pasando, a pesar de que el día contra el racismo se instituyó hace más de cincuenta años, todavía seguimos sufriendo estas situaciones" (Espiro, Voscoboinik y Zubrzycki, 2016).

En consecuencia, a partir del carácter conmemorativo que adquiere la marcha se establece una nueva relación mnemónica que resulta "eficaz para unificar miradas y pensamientos sobre un momento histórico-político" (Carvalho y da Silva Catela 2002: 197), en este caso, promoviendo la visibilización y las medidas reparatorias respecto de la persistencia del racismo y la discriminación sufridos por la población afrodescendiente en Argentina y expresados a traves de la violencia estatal. Podríamos decir que este acto se constituye en un atisbo de invención de una tradición que resulta ajena al calendario oficial de efemérides y cuya continuidad dependerá de las acciones realizadas en los años subsiguientes. El acto conmemorativo además sirve de andamiaje legitimador de los reclamos de justicia, siendo que "la justicia es, sin duda, la parte más sólida de la memoria, y su ausencia se siente en el espacio de las luchas por la conmemoración." (Jelin 2002b: 250). En nota periodística posterior a la marcha, los líderes reflexionaron sobre esta relación:

"Y queremos justicia, sea como sea y para eso contamos con la presión de la gente, con la presión de la sociedad, de los medios de comunicación. Necesitamos estar juntos en esto porque la violencia ahora es contra nosotros, pero mañana va a hacer contra cualquiera de ustedes, porque la violencia no discrimina en ese aspecto. El capitalismo usa la marginación y el racismo como un arma de exclusión y todos en algún momento estamos en ese lugar, no permitamos que esto continúe avanzando."19

"Entonces nosotros asumimos un compromiso desde cada una de nuestras organizaciones pero también desde la Comisión 8 de Noviembre, refrendado por cada uno de ustedes que cotidianamente le dicen también 'no al racismo, no a la discriminación' y a que la memoria del compañero Massar Ba y de tantos otros africanos, afrodescendientes, negros, negras, no afro que son víctimas de la violencia y del racismo. Que sus muertes y crímenes no sean en vano". ${ }^{20}$

Estas demandas se producen en un contexto particular:

\footnotetext{
${ }^{19}$ Según Miriam Gómes en la publicación Resumen, la otra cara de las noticias de América latina y el tercer Mundo,

http://www.resumenlatinoamericano.org/2016/07/04/argentina-elasesinato-del-senegales-massar-ba-y-el-aumento-de-la-violenciainstitucional-contra-los-afrodescendientes/ consultado el 15 de noviembre de 2016.

${ }^{20}$ Carlos Álvarez Nazareno en la publicación Resumen, la otra cara de las noticias de América latina y el tercer Mundo, http://www. resumenlatinoamericano.org/2016/07/04/argentina-el-asesinatodel-senegales-massar-ba-y-el-aumento-de-la-violencia-institucionalcontra-los-afrodescendientes/ consultado el 25 de noviembre de 2016.
}

por un lado, como mencionamos, en el marco de un proceso gradual de visibilización de negritudes y de los racismos operantes sobre esas negritudes, donde los sujetos afro participan como agentes activos en el establecimiento de identificaciones y pasados que legitimen y autoricen sus discursos dentro de una construcción nacional históricamente blanca; y, por el otro lado, en un momento de afianzamiento del campo de la protesta contra la violencia policial en Argentina caracterizado como "espacio de protesta contra el estado" (Pita, 2010:43) aunque, en este caso, sin la centralidad de la figura del familiar.

Es así como se producen demandas de justicia, reconocimiento e inclusión hacia el estado destinadas a reparar el silenciamiento y la opresión de los sujetos de origen africano:

\begin{abstract}
“Nos acercamos a la comisión [ de Derechos Humanos] porque entendíamos que en la Ciudad de Buenos Aires realmente no solamente el crimen de Massar sino también el crecimiento de la violencia policial, institucional, racista está cada vez más tomando nuestros cuerpos, violentándonos con cada una de las distintas acciones que evidenciamos muchas veces en nuestro cotidiano. Y nosotros no queremos dejar de levantar nuestra voz, de dar presencia, de poner el cuerpo, la bandera de resistencia como lo han hecho nuestros antepasados y nuestros ancestros y hoy nosotros continuamos esa lucha".
\end{abstract}

Se trata entonces de una lucha que traza su origen en el repudio hacia el sistema esclavista que comenzó con los antepasados y que encuentra continuidad en la búsqueda de una "ciudadanía sustantiva" que "eleve la calidad de los modos de pertenencia" (Lao Montes 2009) a través de las demandas por políticas afirmativas. En términos de Lao Montes, podríamos pensar la acción de los líderes afroargentinos como reclamos por afro-reparaciones, ya que se encuentran "sustentados en una política de la memoria, de la esclavitud y sus consecuencias y la relación que este pasado de opresión tiene con el presente de desigualdad y posibles futuros de liberación." (2009). De esta forma, la marcha de reclamo y conmemoración se entiende como parte de esas acciones necesarias destinadas a "rescatar memorias colectivas no solo para recordar el terror constitutivo [...] inscrito en la institución de la esclavitud moderna, sino también para revivir memorias de lucha y auto-afirmación de los Afrodescendientes y así revelar [su] agencia histórica." (Lao Montes 2009).

Surgen entonces lecturas alternativas del pasado disponibles en el escenario público que se proponen accionar contra opresiones y racismos devenidos de los sistemas esclavistas pero que se reproducen en los sistemas estatales actuales. $Y$ en este punto volvemos a preguntarnos como Yerushalmi $(1998,26)$ si el antónimo de "el olvido" no sería "la memoria" sino la justicia. 


\section{Reflexiones finales}

A lo largo del trabajo hemos indagado acerca del carácter conmemorativo que adquirió la marcha realizada para demandar justicia por la muerte de Massar Ba. Entendida como crimen racista, la desaparición del líder senegalés nos permitió reflexionar sobre las disputas entre memorias subalternas y construcciones hegemónicas del pasado, sobre el accionar de los líderes o emprendedores de la memoria en la selección de acontecimientos, fechas o personajes del pasado que deben ser evocados, sobre la ambigüedad del posicionamiento estatal frente a las demandas de memoria y justicia, sobre las consecuencias de las nuevas formas de visibilización de negritudes respecto a la (re)aparición del racismo en Argentina. Respecto de esto último nos interesó detenernos sobre la dimensión racial que adquiere la muerte de Massar Ba para los sujetos involucrados en un contexto donde "la raza reencuentra la formulación verbal perdida" (Segato en Caggiano 2015:) y se establece como frente de batalla del discurso público. La racialización del sujeto explica entonces el ejercicio de violencia desde el poder estatal sobre su cuerpo vulnerable. Como señalamos las nuevas construcciones de negritudes requieren establecer procesos, derroteros que legitimen formas actuales de identificación. Por esta razón, las memorias son claves en la reconstrucción de pertenencias e identidades estableciendo orígenes y posicionando trayectorias históricas que autoricen el accionar de grupos con proyectos colectivos frente al estado. En este caso, observamos cómo los actores "se apropian de la fecha y la encuadran en sus propias identidades y proyectos" (Jelin 2002b, 245). Resta por ver si en los años subsiguientes la fecha se consolida dentro del calendario afroargentino y cuáles serán los sentidos que se produzcan, circulen y se transmitan tanto dentro del colectivo como en relación a la genealogía oficial estatal.

Buenos Aires, 20 de octubre de 2017

\section{Referencias bibliográficas}

Caggiano, S. (2015). Imaginarios racializados y clasificación social: retos para el análisis cultural (y pistas para evitar una deriva decolonial esencialista). Cuadernos Inter.c. a.mbio sobre Centroamérica y el Caribe, 12(2), 157-188

Carvalho, A y da Silva Catela, L. (2002). 31 de marzo de 1964 en Brasil: memorias deshilachadas. En E. Jelin (comp.), Las conmemoraciones: Las disputas de las fechas "in-felices" (pp.195-244). Madrid: Siglo XXI Editores.

Espiro, L. (2017) Senegaleses entre la Argentina y el sur de Brasil: etnografía de la movilidad regional y la alternancia laboral entre venta ambulante e industria. En M. Maffia y B. Zubrzycki (Coords.) Africanos y afrodescendientes en Argentina: prácticas, representaciones, narrativas y memorias (pp. 41-60). Buenos Aires: Biblos.
Espiro, L., Voscoboinik, S. y Zubrzycki, B. (2016). Enfrentando el racismo institucional. Análisis de dos casos de migrantes senegaleses en Argentina (2012-2016). REMHU - Rev. Interdiscip. Mobil. Hum., XXIV (48), 63-78.

Frigerio, A. (2006). "Negros" y "Blancos" en Buenos Aires: Repensando nuestras categorías raciales". En L. Maronese, Buenos Aires Negra: Identidad y Cultura (pp. 77-98). Buenos Aires: CPPHC.

Frigerio, A. (2008). De la "desaparición" de los negros a la "reaparición" de los afrodescendientes: Comprendiendo la política de las identidades negras, las clasificaciones raciales y de su estudio en la Argentina. En G. Lechini (Comp.), Los estudios afroamericanos y africanos en América Latina: Herencia, presencia y visiones del otro. Buenos Aires: CLACSO.

Gaztañaga, J., Piñeiro Carreras, J. y Ferrero, L. (2016) Afectos y efectos de Estado: Procesos políticos en torno a la creación de infraestructura, planificación urbana y turistificación. Estudios sociales del Estado, 2 (3), 125153.

Geler, L. (2016). Categorías raciales en Buenos Aires. Negritud, blanquitud, afrodescendencia y mestizaje en la blanca ciudad capital. Runa 37(1), 71-87.

Grimson, A. (2013). Introducción. En A. Grimson y K. Bidaseca (Coords.), Hegemonía cultural y políticas de la diferencia (pp. 9-20). Buenos Aires: CLACSO.

Jelin, E. (2002a). Los trabajos de la memoria. Madrid: Siglo XXI Editores.

Jelin, E. (Comp.). (2002b). Las conmemoraciones: Las disputas de las fechas "in-felices". Madrid: Siglo XXI Editores.

Jelin, E. (2005). Exclusión, memorias y luchas políticas. En D. Mato (Comp.), Cultura, política y sociedad. Perspectivas latinoamericanas (pp. 219-239). Buenos Aires: CLACSO.

Lao Montes, A. (2009). Cartografías del campo politico afrodescendiente en América Latina. Universitas Humanística, 68, 207-245

Monkevicius, P. (2017). Memorias y acción política: Conmemorando el Día del Afroargentino. En V Congreso de la Asociación Latinoamericana de Antropología y XVI Congreso de Antropología de Colombia, Bogotá, 6 al 9 de junio.

Pita, M. V. (2010). Formas de morir y formas de vivir. El activismo contra la violencia policial. Buenos Aires: Ediciones del Puerto. 
Raggio, S. (2017). La memoria en las calles: de la lucha contra la dictadura al reclamo por la desaparición forzada de Santiago Maldonado. Megafón, la batalla de las ideas, 16/4.

Yerushalmil, Y. (1998). Reflexiones sobre el olvido. En Y. Yerushalmi, Loraux, N., Mommsen, H., Milner, J. y
Vattimo, G., Usos del olvido (pp. 13-26). Buenos Aires: Nueva Visión.

Zubrzycki B. (2011). Las dahiras mourides en Buenos Aires. Anclajes locales de la migración senegalesa. En C. Pizarro (Coord), Migraciones Internacionales Contemporáneas. Estudios para el Debate (pp. 187-204). Buenos Aires: Ediciones CICCUS. 